\title{
¿Qué es el feminismo y la teoría de género?
}

\author{
Lorena Robles Brena ${ }^{1}$ \\ Centro Oaxaqueño para la lgualdad $\mathrm{AC}^{2}$
}

Palabras clave:

Bondades del feminismo, teoría de género, mitos sobre feminismo.

\begin{abstract}
Este es un texto de divulgación de la teoría feminista y de género, que expone el feminismo como teoría y movimiento social democrático, liberador e ilustrado. Se abordan sus antecedentes históricos y algunas bondades de esta teoría y práctica política. Asimismo, se revisan los mitos más comunes sobre el feminismo o de las personas que se adscriben a él. Se encuentra el concepto del eje científico-académico del feminismo, la teoría de género, además de categorías conceptuales como, género, sexismo, patriarcado y perspectiva de género.
\end{abstract}

El feminismo es una serie de conocimientos, prácticas y metodologías que buscan la igualdad entre las mujeres y los hombres con el fin de que este mundo sea mejor. En mi experiencia, la teoría y metodología feminista, o como se le suele llamar en el ámbito académico, teoría de género (CONAPO, 2000), ha sido un parteaguas en mi vida, para mejorar.

Gracias a la teoría y el movimiento feminista de siglos atrás (Amorós y Álvarez, 2005), las mujeres gozan en la actualidad de una serie de derechos que para nuestras abuelas eran inconcebibles. El hecho de que estés leyendo este artículo es un logro de muchas mujeres y hombres, que lucharon a favor de la igualdad de derechos. Sin este movimiento, muchas mujeres no sabrian leer y menos escribir. No podrían votar, ir a la universidad, vivir solas, ganar un salario, ejercer una profesión, entre otras cosas.

1 Maestra en Psicología Social y Comunitaria y especialista en teoria de género lorenaroblesbrena@ gmail.com

2 Ubicada en Sabinos 517 interior 4, Colonia Reforma. C. 68050, Oaxaca, México. ceoigualdad@hotmail. com 
A pesar de todos estos beneficios, hay voces que desprestigian y difaman al feminismo generando con ello desinformación respecto a esta propuesta, que tiene como único objetivo un mundo mejor, con mayor igualdad, justicia y bienestar para toda la humanidad, sin importar su sexo. Este desprestigio se debe a que el feminismo es una teoría crítica, que señala los puntos donde hay que cambiar nuestras formas de ver y hacer las cosas y, frente al cambio, habitualmente hay muchas resistencias, sobre todo si tal cambio les quita ciertos privilegios a algunos (Varela, 2008).

\section{Entonces, ¿qué es el feminismo y para qué nos es útil?}

El feminismo ha sido un movimiento filosófico y político que busca construir sociedades más democráticas a través de la igualdad de derechos entre las mujeres y los hombres. El feminismo se ha construido en dos grandes pilares (Amorós y Álvarez, 2005); un pilar teórico que se alimenta de diversas disciplinas científicas, tales como sociología, historia, antropología, psicología y la filosofía en diversas ramas y, especialmente, filosofía política y ética. El otro pilar es el movimiento de mujeres de todo el mundo, pertenecientes a diversas culturas, contextos, oficios, quehaceres y perspectivas.

El feminismo surge oficialmente durante la llustración (movimiento intelectual, principalmente en Francia e Inglaterra) y la Revolución francesa (movimiento social, 1789-1799). Aunque hay antecedentes de hace ya tres siglos de filósofos cuestionando que las desigualdades entre mujeres y hombres sean naturales, como lo hicieron Marie De Gournay (1565-1645) y Poulain de la Barre (1647-1723).

La teoría de género, es entonces, la rama del feminismo más actual y académica. Surge en varios paises y tiene gran auge en las universidades estadounidenses desde la década de 1940 hasta la década de 1960. Posteriormente los estudios feministas y de género, se llevan a cabo en todo el mundo con diversas propuestas y aplicaciones. Asimismo, se ha desarrollado una metodología para analizar cualquier área de la vida humana desde este enfoque y desarticular las desigualdades entre hombres y mujeres. A esta herramienta metodológica se le denomina perspectiva o enfoque de género (CONAPO, 2000).

Cuando se menciona "género" se está hablando de las ideas, creencias, normas y mandatos sobre ser mujer y ser hombre que nos enseñan durante nuestra vida en todas las instituciones sociales como hogar, escuela, trabajo, grupo de amistades, medios de comunicación, etc. (Serralde y Ugalde, 2007) y, que se ha comprobado que no están relacionadas con la biología. 
¿Qué es el feminismo y la teoría de...

En otras palabras, las mujeres no nacen con una inclinación genética al color rosa, a la limpieza o a la cocina, así como tampoco los hombres nacen con una preferencia natural hacia las herramientas, los autos o el fútbol.

La teoría de género o feminista es una teoría liberadora para hombres y mujeres, ya que permite ver cómo los estereotipos y mandatos de género limitan el desarrollo y potencial de los seres humanos. Es decir, una mujer puede tener habilidades para construir grandes obras de arquitectura, pero como la construcción es un área considerada como "masculina" desde el punto de vista social, ella no tendrá las mismas oportunidades como un hombre para desarrollar su potencial. A un hombre que tiene habilidades para la danza, considerada socialmente como un ámbito femenino, se le cuestionará su virilidad o su orientación sexual. Por tanto, no será motivado por su entorno cercano a desarrollarse libremente en tal área.

Para poder comprender un poco más sobre qué es o no el feminismo, resulta importante responder algunas preguntas y/o mitos que suelen hacerse comúnmente en torno al tema:

¿Cuál es el objetivo del feminismo? Que los seres humanos tengamos todas las condiciones para desarrollar libremente nuestro potencial, habilidades, aptitudes, sin cuestionarse si tal o cual actividad es de hombres o de mujeres. Habitualmente se cree que el feminismo, o quien suscribe esa teoría o al menos sus propuestas, es una persona resentida y con ganas de venganza. Puede haber personas que utilicen la teoría para ello, pero el feminismo no nace así, su objetivo no es la venganza y su motivación no es el resentimiento, sino el interés de que las personas estén mejor. Se ha comprobado que cuando las mujeres tienen mayor educación, salud e ingresos, los índices de desarrollo y bienestar de las personas cercanas a ellas, se elevan (Wilde, 2001). Es lógico, si el 52\% de la población mundial está mejor, este mundo se encuentra mejor.

La idea de que el feminismo es una guerra de sexos es errónea. El feminismo no se trata de competencia para ver quién es mejor moral o intelectualmente, si ellas o ellos. No es una teoría que esté en contra de los hombres, es una teoría que aspira a la igualdad de derechos y a la justicia para mujeres y para hombres.

¿Las feministas son lesbianas? Algunas sí y otras no. La orientación sexual de una persona, no depende de que se adscriban a una teoría. También hay lesbianas que no son feministas, ni pretenden serlo. Hay mujeres heterosexuales no feministas y feministas. 
¿El feminismo está peleado con las religiones? El feminismo hace ver, por eso es una teoría crítica (Amorós, 1995), aquellas prácticas de las diversas instituciones sociales que no respetan los derechos fundamentales de las personas, que limitan libertades, someten o dañan a las personas. Así que algunas prácticas humanas en las instituciones religiosas son señaladas por ser sexistas ${ }^{3}$ o patriarcales ${ }^{4}$.

El feminismo, o teoría de género, nos son útiles entonces, para transformar la realidad, nos brindan herramientas teóricas, prácticas, metodológicas y políticas para lograr mayor igualdad y justica. Es de los instrumentos más poderosos para construir sociedades democráticas, ya que de todos los grupos marginados o sin ejercer plenamente sus derechos, la mitad son mujeres. Además, es de los pocos movimientos político-sociales que utiliza formas pacíficas, sin armas para visibilizar sus propuestas. También es una teoría y práctica para la libertad; sirva entonces este breve artículo como invitación para conocer más de sus propuestas, historia, feministas, metodología y beneficios para cada persona.

\section{Referencias}

Amorós, C. (1995). 10 palabras clave sobre mujer. Navarra: Verbo Divino. Amorós, C. (1995). Presentación. En Amorós, C. (directora), 10 palabras clave sobre mujer (17-20). Navarra: Verbo Divino.

Amorós, C. y Álvarez, A. (2005) Teoría feminista: de la ilustración a la globalización. Madrid: Editorial Minerva. Introducción: de la teoría feminista y movimientos feministas,. Amorós, C. \& Álvarez, A. (2005). En .Amorós, C. \& Álvarez, A. (coordinadoras) Teoría feminista: de la ilustración a la globalización (Madrid: (13-90) Editorial Minerva

Blogs Unileón. Glosario conceptos básicos feminismo. [Acceso 30 de marzo 2018]. Recuperado de: http://blogs.unileon.es/educa/files/2016/07/Glosario.pdf.

conapo. Consejo Nacional de Población. La perspectiva de género. Guía para diseñar, poner en marcha, dar seguimiento y evaluar proyectos de investigación y acciones públicas y civiles. México; 2000

Serralde, S., y Ugalde, Y. (2007). Glosario de género. [Acceso 30 marzo 2018]. Recuperado de: http://cedoc.inmujeres.gob.mx/documentos_download/100904.pdf Ciudad de México: Instituto Nacional de las Mujeres (InMUJERES).

3 El sexismo, es la discriminación basada en el sexo.

4 El patriarcado es uno de los conceptos principales de la teoría de género que se refiere a la concentración del poder en los ámbitos, económico, militar, científico, político, social, etc., por parte del colectivo de varones (Unileón, 2016). El patriarcado, también exige a los hombres comportamientos, intereses, normas, etcétera, que vayan de acuerdo a este sistema. 
¿Qué es el feminismo y la teoría de...

Wilde, V. (2001). Manual para nivel del Campo. Programa de Análisis Socioeconómico y de Género (ASEG). Roma: Organización de las Naciones Unidas para la Agricultura y la Alimentación (FAO).

Varela, N. (2008) Feminismo para principiantes. Prejuicios y tópicos. Varela, N. (2008). En Varela, N. (autora). Feminismo para principiantes (288-301) Barcelona: Ediciones B. 